\title{
Clinical Trials methodology and elderly
}

\author{
E D Di Paola*, S De Fazio, P Gareri, E Russo, G De Sarro \\ From de Senectute: Age and Health Forum \\ Catanzaro, Italy. 5-7 December 2009
}

Due to the ageing of the population and the sharp increase in life expectancy, cancer diagnosed in the elderly population is rising and it has become an increasingly common problem in the Western world. According to the National Cancer Institute (NCI), for all cancers combined, the incidence rate in people 65 and over is 10 times higher than the rate for younger people, and the mortality is 16 times higher. The number of people in the United States who are 65 and older is expected to double by year 2030 .

A study published in 1999 in the New England Journal of Medicine found that while $63 \%$ of people in the general population age 65 or older had cancer, only $25 \%$ of patient in that age group were represented in clinical trials.

The cut-off point at which an adult is considered 'elderly' has not been well defined. Usually, age 70 years is considered a reference point and is commonly used in clinical trials in oncology.

One of the most intriguing aspects of ageing is how different the ageing process is from person to person; the basis for this variation is largely unknown.

Clinical trials are generally used for the clinical development on new drugs/strategies. They are divided in three consecutive phases (I, II and III). The firsts two aim to characterize the action and to archive all knowledge necessary for better mange the experimental drugs. For all these reasons it is important to allow the inclusion of selected people without comorbidities that can interfere with the results. In contrast, phase III trials, considered the last step before registration, aim to demonstrate the efficacy/utility of the experimental $\mathrm{drug} /$ strategies on a number of patients representing the whole population of patients for a selected pathology.

If it is tolerable to limited the participation of elderly patients, for their frailty, comorbidities or different metabolism, in the inclusion of phase I or dose finding

Chair of Clinical and experimental Pharmacology, Faculty of Medicine and Surgery, University Magna Graecia of Catanzaro, Italy and Phase II trials it is not acceptable to exclude them in the large phase III.

Furthermore, it is now clear that Chronologic age cannot be used to predict the degree of comorbidity and of functional deterioration of the single individual up to age 85 at least; Performance status, which takes into account level of activity, ambulation, and ability to care for oneself-and the presence of comorbid conditions that may be exacerbated by treatment are more reliable criteria for clinical trial eligibility than age.

In conclusion age alone should never make a patient ineligible for a trial.

Published: 19 May 2010

doi:10.1186/1471-2318-10-S1-L62

Cite this article as: Di Paola et al:: Clinical Trials methodology and elderly. BMC Geriatrics 2010 10(Suppl 1):L62.

Submit your next manuscript to BioMed Central and take full advantage of:

- Convenient online submission

- Thorough peer review

- No space constraints or color figure charges

- Immediate publication on acceptance

- Inclusion in PubMed, CAS, Scopus and Google Scholar

- Research which is freely available for redistribution

Submit your manuscript at www.biomedcentral.com/submit
C Biomed Central 